\title{
Emotional Intelligence of Prospective Teachers With Reference To Certain Biographical Factors
}

\author{
${ }^{1}$ Dr. Sunil Trivedi, ${ }^{2}$ Arti Shakya (M.Phil.) \\ Institute of Education, Bundelkhand University, Jhansi (U.P.), India
}

\begin{abstract}
The present research was conducted on prospective teachers to analyze their Emotional Intelligence in relation to Gender, Caste and SES. For the purpose a sample of 300 (150 male and 150 female) prospective teachers was selected from the B.Ed. Colleges affiliated to Bundelkhand University, Jhansi by using semiprobability sampling techniques. Emotional Intelligence Test constructed by K.S. Mishra and self-made General Information sheet were used to collect the data. Results revealed that the there is a significant difference in the mean of emotional intelligence scores of the male and female prospective teachers. The prospective teachers belong to GEN category scored high on emotional intelligence scale as compared to the OBC \& SC prospective teachers. The levels of SES of prospective teachers do not cause significant variation in emotional intelligence.
\end{abstract}

\section{Introduction}

Many psychologists and educationists have been trying to bridge the gap between the success and discomfiture caused by head (value) and heart (devalue). This logical inquiry continues over the years not only in developing countries like India but all over the world, psychologists Mayer, et al (1989) came with an answer by introducing the concept of Emotional Intelligence, through it was referred by various names - from smartness and personality to soft skills and competence.

Research has suggested that intelligence is broader than the narrow cognitive domain measured by traditional intelligence tests and in fact, contributes only about $20 \%$ to the factors that determine life success (Gardner, 1995). Recently, Emotional intelligence, a construct that includes much of Gardner's theory, has emerged as key factor in research investigating a range of outcomes including academic achievement and employment success (Goleman, 1995, 1998: Salovey \& Mayer, 1989-1990).

Goleman (1995) described Emotional Intelligence as an ability that includes self-awareness, impulse control, persistence, zeal, self-motivation, empathy and social adaptness. Bernet (1996) operationalized emotional intelligence by focusing on optimal responses that result from the ability to attend rapidly appropriately and without effort to the experienced feelings an inability in this area leads to self-damaging emotions and behaviour. In other words, Emotional Intelligence refers to the skillfulness with which one can regulate the emotions of oneself and others.

Therefore, Emotional Intelligence is the ability to sense, understand, and effectively apply the power and acumen of emotions as a source of human energy, information, connection and influence. It is believed that Emotional Intelligence is the basis of all success in human life. Yate (1997), listed various jobs on the basis of the level of Emotional Intelligence requiring success and satisfaction. From the list it is clear that a teacher requires the very high level of Emotional Intelligence to deal with students as compared to a Botanist who may require a lower level of Emotional Intelligence.

Development of nation depends on its devoted citizens and these citizens are shaping in classroom so it is very clear that we need very devoted and sincere teachers to teach them. It is very important that only high emotionally intelligent peoples should come in this teaching profession. Being emotional intelligent for a teacher is very important because students always follow their teachers. Emotionally intelligent teacher can handle the emotion of teenagers effectively. Our classroom settings demand that student-teachers must learn how to appreciate and accept differences in emotional expressions and management among students. Emotions are an important part of one's personality. They determine the nature and effectiveness of the pattern of social interaction and also contribute to the psychological well-being of an individual. If our prospective teachers are emotionally intelligent, they will be able to express their emotions positively without threatening students or other persons. An attempt has been made in this study to find out that does emotional intelligence is related to some biographical factors?

\section{Literature Reviewed}

McDowell and Bell (1997) found that lack of emotional intelligence skills lowered team effectiveness and created dysfunctional team interactions and most effective performers lost the best networking skills. Tapia and Marsh (2001) found an overall significant main effect of gender and two-way interaction of gender - GPA 
on emotional intelligence. Annaraja and Jose (2005) found that rural and urban B.Ed., trainees did not differ in their self-awareness, self-control, social skills and emotional intelligence. Devi and Uma (2005) found that the parental education, occupation had significant and positive relationship with dimensions of emotional intelligence like social regard, social responsibility, impulse control and optimism. Harrod and Scheer (2005) found that emotional intelligence levels were positively related to females, parents' education and household income. Amirtha and Kadhiravan (2006) found that gender, age and qualification influenced the emotional intelligence of school teachers. Mishra (2006) has studied the teaching work motivation among emotionally intelligent student-teachers. He found that as compared to high emotionally intelligent student-teachers; less emotionally intelligent student-teachers have less teaching work motivation. For highly emotionally intelligent student-teachers emotional intelligence was found to be positively related to teaching work motivation. But for less emotionally intelligent student-teachers the relationship was not significant. Updhyaya (2006) has studied the personality of emotionally intelligent student-teachers on a sample of 78 student-teachers. It was found that as compared to low emotionally intelligent student-teachers, high emotionally intelligent student-teachers are more confident, persistent, supportive, enthusiastic and divergent. Parker et al (2006) had studied the emotional intelligence of 464 Principals or Vice Principals from the elementary and secondary schools and found that women scored higher than men on the interpersonal dimension of emotional intelligence. Also task-oriented Principals are found to have impulse control, self awareness, assertiveness, self actualization, empathy, social responsibility, interpersonal relations, adaptability, problem solving, independence, stress tolerance, optimism and happiness, Gender, interpersonal, intrapersonal relations and adaptability were found to be the predicator of task oriented Principals and Vice Principals. Michael (2005) has studied the emotional intelligence and faculty qualities necessary for success in a non-traditional classroom setting. Results revealed that there is no significant relationship between scores of emotional intelligence and scores on the student end-of-course evaluations. Also both faculty who scored high and low in assessment of emotional intelligence stressed flexibility and strong interpersonal relationship skills in the classroom. Faculty members who scored high on emotional intelligence assessment demonstrated more optimism than those who scored low on the assessment of emotional intelligence. Priyadarshini (2005) found that there is a significant difference in the perception of male and female staff members with respect to their perception towards the components of emotional intelligence such as emotional sensitivity, emotional maturity and emotional competence. Majority of the staff members have got moderate emotional intelligence. Males and females are having moderate EQ though females were higher on emotional intelligence than men. It has been also found that there is significant difference between emotional intelligence with respect to educational level and emotional intelligence increases with increase in the span of experience and experience is found to be the most important factor of emotional intelligence. Analysis of teachers qualities by Sibia, Mishra \& Srivastava (2004) shows that teachers who are affectionate and cooperative, have control over negative emotions and are friendly, were found to be emotionally successful. Children also admire teachers who are dedicated and show empathy and concern, are responsible and have a happy disposition. Creative, unbiased, confident, helpful, and optimistic and fearlessness were some other characteristics mentioned by the children while stating the favorite qualities of their favorite teacher. Children's responses indicate that they like teachers who are disciplined, regular, punctual, well-behaved, available for students, serious about the studies, and make extra effort to reach out to each and every student. Okech (2004) has examined the relationships among emotional intelligence, teacher's self-efficacy, length of teaching experience and age in a sample of South Texas Public School teachers. A significant positive relationship was found between emotional intelligence and teacher's self- efficacy. But there was no significant relationship between "emotional intelligence" and "length of teaching experience" and between "emotional intelligence" and "age". Male and female teachers are found to be different on "emotional intelligence". Perry, Ball and Stacey (2004) have studied about a measure of emotional intelligence that relates directly to the work of teachers in schools and the levels of emotional intelligence held by teachers at the beginning of their career. Categorical finding based on gender, faculty, age-group and teaching focus shows that (i) a strong and significant gender difference exists on emotional intelligence reactions (ii) Emotional intelligence is directly related to the understanding of teaching motivation and self directed learning of student- teachers. Singh (2003) has studied the emotional intelligence and adjustment of teachers working in different levels of education. He found that there is a significant positive relationship between emotional intelligence and adjustment. Teacher working in higher educational institution have better emotional intelligence and adjustment in comparison to the teachers in secondary and primary schools. Tucker, Sojka, Barone and McCarthy (2004) found that EQ training program with the help of an instructor is essential for improvement as well as for assuring the success of any teaching and learning activity. Above studies found relationship between emotional intelligence and some other factors. In some cases if found significantly related and in some cases don't.

Hwang (2007) in a study found that EI skills were significantly related to teaching effectiveness among the sampled teachers. A study was conducted by Liang (2007) on relationship between personality type and 
emotional intelligence in a sample of college and university faculty in Taiwan and found a significant relationship function between faculty's personality type \& EI skills and their age \& EI skills; but not between gender and EI skills. Sameer (2008) found no significant difference among the students based on stream of study, marital status and age, except in the comparison of them in their self-esteem based on age. In a study reported in a paper, Moafian, et al. (2009) examined the relationship between Iranian EFL teachers' emotional intelligence and their self-efficacy in language institutes. Data analysis and statistical calculations revealed that there is a significant relationship between the teachers' emotional intelligence and their self-efficacy. Shakya (2009) found that the female prospective teachers appear to be more effective in teaching and less emotionally intelligent as compared to male prospective teachers. The prospective teachers belong to GEN category is more emotionally intelligent than prospective teachers belong to $\mathrm{OBC}$ and $\mathrm{SC}$ category but there is no significant difference in Teaching Effectiveness between prospective teachers of GEN \& SC and GEN \& OBC category. In a study, Kauts and Saroj (2010) found that teachers with high emotional intelligence were having less occupational stress and more teacher effectiveness, whereas, teachers with low emotional intelligence were having more occupational stress and less teacher effectiveness. Singaravelu (2011) found No significant difference in emotional intelligence between men and women student teachers while significant difference was observed in emotional intelligence between the groups regarding locality of the residence of student teachers.

\section{Objectives}

1. To study the Emotional Intelligence (EQ) of Prospective Teachers in relation to their Gender.

2. To study the Emotional Intelligence (EQ) of Prospective Teachers in relation to their Caste.

3. To study the Emotional Intelligence (EQ) of Prospective Teachers in relation to their Socio-economic Status.

\section{Hypotheses}

1. There exists no significant difference in Emotional intelligence of male and female Prospective Teachers.

2. There exists no significant difference in Emotional intelligence among Prospective Teachers of various Caste groups.

3. The levels of Socio-economic Status of prospective teachers do not cause significant variation in Emotional intelligence.

Method

\section{Methodology}

The researcher employed the "Descriptive Survey Method".

\section{Sample}

A sample of 300 (150 male and 150 female) prospective teachers was selected from the B.Ed. Colleges affiliated to Bundelkhand University, Jhansi by using semi-probability sampling techniques.

\section{Tools}

1. Test of Emotional Intelligence constructed by K.S. Mishra was used for measuring Emotional Intelligence.

2. General Information Sheet constructed by researcher was used for measuring SES.

Statistical Techniques

For the analysis of the data the Mean, Standard Deviation and CR test were used.

\section{Results And Discussion}

\subsection{Comparison Of Emotional Intelligence Of Male And Female Prospective Teachers}

One of the objective of the study was "To study the emotional intelligence of prospective teachers in relation to sex." To fulfill this objective a comparison was made between means of emotional intelligence of male and female prospective teachers.

The mean values of emotional intelligence scores for male and female have been found 69.92 and 67.45 respectively, which shows that the both groups have difference in their emotional intelligence. Male have high level of emotional intelligence in comparison to female.

The Statistical evidences are in favour of general observations that the emotional intelligence of male and female are not equal. To go in to the detail and to find out the validity of observation the CR values were calculated and presented in table 1.1 given below. 
Table-1.1: Mean, SD and CR Values of Emotional Intelligence Scores of male and female prospective teachers

\begin{tabular}{|l|l|l|l|l|l|l|}
\hline \multicolumn{1}{|c|}{ GROUPS } & N & M & SD & CR & df & p \\
\hline MALE & 150 & 69.92 & 9.43 & \multirow{2}{*}{2.38} & 298 & $<.05$ \\
\hline FEMALE & 150 & 67.45 & 8.52 & & & \\
\hline
\end{tabular}

It is evident from the table that the $\mathrm{CR}$ value for male and female prospective teachers is significant at .05 level for df 298. Results are showing that there is significant difference in the mean of emotional intelligence scores of the male and female prospective teachers. Thus the hypothesis that "there exists no significant difference in Emotional intelligence of male and female Prospective Teachers" is rejected.

This reveals that male and female prospective teachers are not equal in their emotional intelligence level i.e. male prospective teachers have high level in Self-awareness, Self- regulation, Motivation, Empathy and Social Skills in comparison to their counterparts i.e. female. Reason behind this may be that, there is a discrimination between male and female, in providing them equal opportunities for expose their emotions and abilities. As a result male develop higher level of emotional intelligence in them in comparison to female. A pictorial representation (vide fig-1) of the means of emotional intelligence of the two groups i.e. Male and female prospective teachers, also confirm this fact.

This Study not corroborates with the study of Singh (1993), Richardson (2000), Dearkser (2002) and Sharma (2003), which shows that both male \& female groups have adequate emotional maturity and emotional intelligence to deal with environment. The studies conducted by Reiff (2001) and Hopkins (2005), however, supports the findings of this study.

\subsection{Comparison Of Emotional Intelligence Of Prospective Teachers Among Various Caste Groups}

In order to find which caste group of prospective teachers is better in Emotional Intelligence, the mean and CR values of three groups were calculated and compared. The obtained results are presented in the table- 2.1

Table-2.1 Mean, SD and CR values of Emotional Intelligence Scores of prospective teachers of various caste groups

\begin{tabular}{|c|c|c|c|c|c|c|}
\hline GROUPS & $\mathbf{N}$ & $\mathbf{M}$ & SD & CR & df & p \\
\hline GEN & 107 & 72.13 & 7.78 & \multirow{2}{*}{2.83} & \multirow{2}{*}{215} & \multirow{2}{*}{$<.01$} \\
\hline OBC & 110 & 69.43 & 6.20 & & & \\
\hline GEN & 107 & 72.13 & 7.78 & \multirow{2}{*}{6.47} & \multirow{2}{*}{188} & \multirow{2}{*}{$<.01$} \\
\hline SC & 83 & 63.25 & 11.12 & & & \\
\hline OBC & 110 & 69.43 & 6.20 & \multirow{2}{*}{3.66} & \multirow{2}{*}{191} & \multirow{2}{*}{$<.01$} \\
\hline SC & 83 & 63.25 & 11.12 & & & \\
\hline
\end{tabular}

A careful perusal of the table 2.1 reflects that on emotional intelligence scale, the prospective teachers belong to GEN category scored high as compared to the OBC \& SC prospective teachers. The CR values show that the difference between emotional intelligence of GEN \& OBC ; GEN \& SC and OBC \& SC prospective teachers are statistically significant at 0.01 level. Pictorial representation (vide fig-1) also support this fact.

Hence, the hypothesis that was framed in this context that there exists no significant difference in Emotional Intelligence among Prospective Teachers of various Caste groups was rejected and it was concluded that there is significant difference between the Emotional Intelligence of prospective teachers of various caste group. This reveals that prospective teachers belong to GEN category have high level in Self-awareness, Selfregulation, Motivation, Empathy and Social Skills in comparison to their counterparts i.e. prospective teachers belong to OBC and SC category.

\subsection{Comparison Of Emotional Intelligence Of Prospective Teachers Among Various Levels Of Socio-Economic Status}

To study the effect of Socio-Economic Status on Emotional Intelligence, first of all, the total sample of prospective teachers was categorized into three groups i.e. high, average and low Socio-Economic Status.

To categorize the total sample into three categories as high, average and low, the mean and standard deviation of Socio-Economic Status scores were considered. The Prospective teachers who scored $61(M+1 \sigma) \&$ above on SES Scale were considered as high in Socio-Economic Status. The prospective teachers who scored 42 $(\mathrm{M}-1 \sigma) \&$ below on the SES Scale were considered as low Socio-Economic Status, while prospective teachers who scored in between the scores $61 \& 42$ were considered as average in Socio-Economic Status. To compare the three groups of prospective teachers on their Emotional Intelligence, the critical ratio test was applied. The results obtained are shown in the table given below 
Table 3.1 Mean, S D And CR Value Of Emotional Intelligence Of High, Average \& Low SES Prospective Teachers

\begin{tabular}{|c|c|c|c|c|c|c|}
\hline GROUPS & $\mathbf{N}$ & M & SD & CR & df & $\mathbf{p}$ \\
\hline LOW SES & 56 & 68.52 & 10.04 & \multirow{2}{*}{0.21} & \multirow{2}{*}{233} & \multirow{2}{*}{$>0.05$} \\
\hline AVERAGE SES & 179 & 68.80 & 8.64 & & & \\
\hline LOW SES & 56 & 68.52 & 10.04 & \multirow{2}{*}{0.01} & \multirow{2}{*}{119} & \multirow{2}{*}{$>0.05$} \\
\hline HIGH SES & 65 & 68.49 & 9.44 & & & \\
\hline AVERAGE SES & 179 & 68.80 & 8.64 & \multirow{2}{*}{0.24} & \multirow{2}{*}{242} & \multirow{2}{*}{$>0.05$} \\
\hline HIGH SES & 65 & 68.49 & 9.44 & & & \\
\hline
\end{tabular}

The results of the above table indicate that prospective teachers either high, average or low SES are same in emotional intelligence. Further among the three groups, average SES prospective teachers either male or female are high in emotional intelligence than the high and low SES prospective teachers. When the three groups of prospective teachers i.e. high, low and average SES are compared in emotional intelligence, it is found that all the groups have equal emotional intelligence. As all the C.R. values are found statistically insignificant at .05 level of confidence. Thus, the hypothesis of the study, "the levels of Socio-economic Status of prospective teachers do not cause significant variation in Emotional intelligence" is accepted.

The relationship between the emotional intelligence and socio-economic status of prospective teachers was further studied by computing the coefficient of correlation. The results are presented in table 3.2

Table 3.2 : Correlation Between Emotional Intelligence And SES Scores Of The Prospective Teachers

\begin{tabular}{|l|l|}
\hline Coefficient of Correlation & Significance Level \\
\hline $0.13^{*}$ & $<.05$ \\
\hline
\end{tabular}

The statistical facts mentioned in the table 3.2 depict that Emotional Intelligence of prospective teachers is significantly related with Socio-Economic Status $(r=0.13)$. The correlation reveals the fact that emotional intelligence do not operate independently but with the increase in scores of SES, emotional intelligence also increases and vice versa.

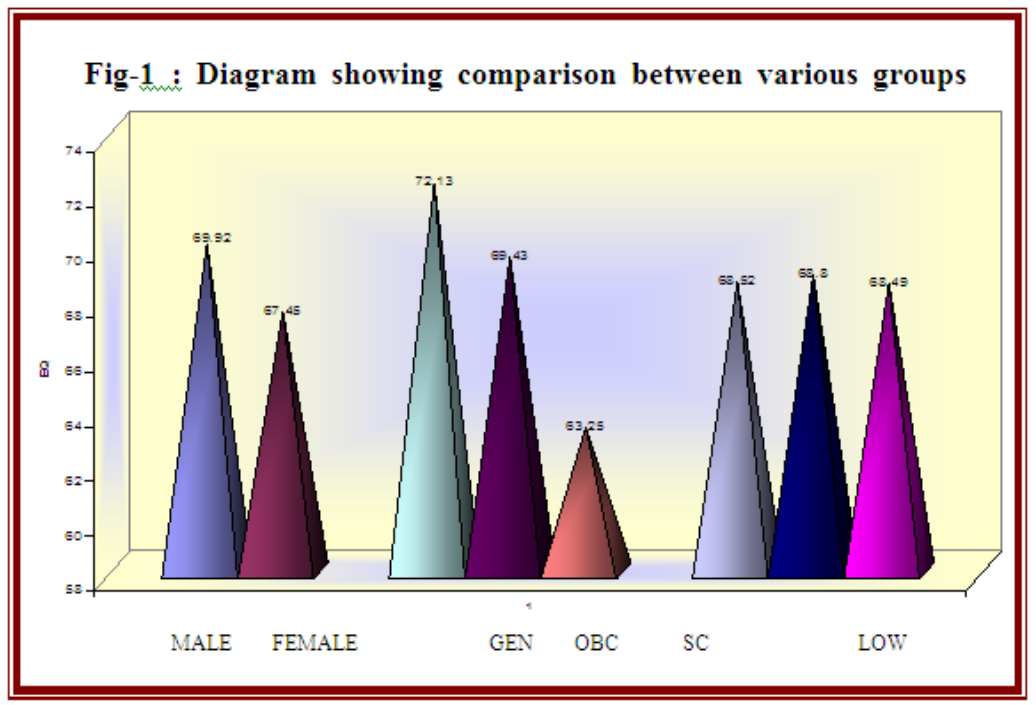

\section{Conclusion}

D There is significant difference in the mean of emotional intelligence scores of the male and female prospective teachers. Male prospective teachers have high level in Self-awareness, Self- regulation, Motivation, Empathy and Social Skills in comparison to their counterparts.

> Prospective teachers belong to GEN category scored high as compared to the OBC \& SC prospective teachers. Difference between emotional intelligence of GEN \& OBC; GEN \& SC and OBC \& SC prospective teachers are statistically significant.

> Prospective teachers either high, average or low SES are statistically same in emotional intelligence. Among the three groups, the mean of average SES prospective teachers either male or female is high in emotional intelligence than the high and low SES prospective teachers. 


\section{Educational Implications}

For the proper development of a nation, it is most essential that educational system must be well organized. The key point in the total system is the teacher and he plays an active role in the formation of the habits, attitude, and other qualities among the students. It is needless to say that how important role of a effective, satisfied and high emotionally and spiritually intelligent teacher in the development of a right type teaching learning environment in the school.

One of the most important aspect of a life is his proper Emotional development. The Emotional and spiritual development of student is not a spontaneous process but it be give from his childhood. Only a well emotionally and spiritually developed person can have a static personality, which is essential for better survival in their educational \& professional life.

To make teachers high emotionally intelligent, better institution environment should be provided as well all are familiar with the fact that environment plays a pivoting role in development of emotional intelligence. Only emotionally intelligent person can handle his emotions competently. To achieve high emotional intelligence, teachers must learn to get a perspective on situation which otherwise would lead to emotional reactions. They can do this best by discussing their problems with others. They must also learn to use emotional catharsis to clear their systems of pert up emotional energy. A teacher, who has high Emotional intelligence, can teach effectively and live in society with better understanding. Emotional Intelligence is remarkable construct and all aspirants for success in the social life and profession chosen depends upon Emotional Intelligence.

Training institution can be greatly benefited by making it a point to assess these aspects of student teachers at the time of admission in training institution so that individuals with proper characteristics may be selected for teacher training programmes. Training institution may also provide such situations to the prospective teachers in training period through which they may develop those characteristics, which are useful in enhancing emotional intelligence.

The findings of this study may also be helpful to the authorities of educational institutions. Administrative authorities may also realize the importance of the emotional intelligence of teachers. The present investigation suggests that educational authorities should concentrate their attention not only on academic qualifications, but also on the emotional intelligence of teachers at the time of requirements. This Study can provide new ways of thinking for better planning \& effective execution of educational programmes.

The findings of this study may also be helpful to the principals of schools. Principal may encourage more of mutual understanding, cooperativeness, esprit de corps and cause less of psychophysical hindrances, threat, alienation and control. They should provide opportunities to teachers to participate in decision-making process, teamwork and expression of ideas for improvement. If such atmosphere is created, teachers are sure to drive higher teaching effectiveness, which in turn, is likely to lead to their greater identification with their institution and its various activities.

The present investigation has revealed that there exists a significant difference in emotional intelligence of male and female teachers. Male teachers are found more emotionally intelligent than the female teachers. This has implications for qualitative improvement of teaching. In order to improve the quality of teaching particularly in the girls schools it seems necessary to make efforts to help the male teachers to develop to emotional intelligence. If this is the case, development of emotional intelligence in the teachers seems to be important from the point of view of qualitative improvement of teaching.

\section{References}

[1]. Amirtha, M. and Kadheravan, S. (2006) Influence of personality on the emotional intelligence of teachers. Edu Tracks 5, 12, 25-29.

[2]. Annaraja, P. and Jose, S. (2005) Emotional intelligence of B. Ed. trainees. Research and Reflections in Education 2, 8-16.

[3]. Bernet, M. (1996, August). Emotional Intelligence : Components and Correlates. Paper presented at the annual Meeting of the American Psychological Association. Toronto, Canada

[4]. Devi, U.L. and Uma, M. (2005) Relationship between the dimensions of emotional intelligence of adolescents and certain personal social variables. Indian Psychological Review 64, 01, 11-20.

[5]. Gardner, H. (1995). 'Cracking open the IQ box', The American Prospect, winter (20), 71

[6]. Goleman, D. (1995). 'Emotional intelligence', New York : Bantam.

[7]. Goleman, D. (1995). Emotional Intelligence: Why it can matter more than IQ. New York: Bantam Books.

[8]. Goleman, D. (1998). Working with emotional intelligence. New York : Bantam,

[9]. Harrod N S \& Scheer S D (2005) An exploration of adolescent emotional intelligence in relation to demographic characteristics. From http://www.findarticles.com /p/articles/mi-m2248/is_159_40/ai_15950403/pg_9

[10]. Hwang, F. F. (2007). The relationship between emotional intelligence and teaching effectiveness. Texas A\&M University Kingsville, USA. Cited in Dissertation Abstract International-B Vol.69, No.10.

[11]. Kauts Amit and. Saroj Richa (2010). Study of Teacher effectiveness and occupational Stress in relation to emotional intelligence among teacher at secondary stage. Journal of history and social sciences. Volume: I, Issue: I, July - December 2010

[12]. Liang, Y. (2007). The relationship between personality type and emotional intelligence in a sample of college and university faculty in Taiwan. Texas A \& M University - Kingsville, USA. Cited in Dissertation Abstract International-A Vol.68, No.07.

[13]. Mayer, J.D. \& Salovey, P. (1997). What is emotional intelligence? Cited in P. Salovey \& D. Sluyter (Eds), Emotional Development and Emotional Intelligence: Implications for Educators. New York : Basic Books. 
[14]. McDowell, J. O. \& Bell, E. D. (1997). Emotional Intelligence and Educational Leadership atEast Carolina University. Paper presented to the Annual Meeting of the National Council for Professors of Educational Administration, East Carolina University, August,1997.

[15]. Michael, P. (2005). An analysis of emotional intelligence and faculty qualities necessary for success in non-traditional classroom setting. Ph.D. Walden University. Dissertation Abstract International, 2005, 66(7), 2465-A.

[16]. Mishra, M. (2006). Teaching work motivation among emotionally intelligent student-teachers. Journal of Educational Studies, 4 (1 \& 2), 40-41.

[17]. Moafian, et al. (2009). An emotional-intelligence-based model for improving faculty members' effectiveness. African Journal of Business Management Vol. 4(14), pp. 3086-3095, 18 October, 2010.

[18]. Okech, Allan P. (2004). An exploratory examination of the relationships among emotional intelligence, elementary school science teachers, self-efficacy, length of teaching, experience, race/ ethnicity, gender and age. Ed.D., Texas A \& M University, Kingsville. Dissertation Abstract International, 2005, 65(8), 2902-A.

[19]. Parker, J.D.A., Stone, H., Wood, L.M. (2006). Report on the Ontario Principal's Council Leadership Study. Ministry of Education and Training, Ontario, Canada.

[20]. Perry, Ball \& Stacey (2004). Cited in Chriss Perry and Ian Ball (2005). Emotional Intelligence and teaching: Further validation evidence. Issues in educational Research, 15.

[21]. Priyadarshini, R.R.G. (2005). A study of emotional intelligence among academic professionals. Journal of Management and Research, April 2005.

[22]. Reiff, H. et al. (2001). The Relation of LD and Gender with Emotional Intelligence in college students. Journal of Learning Disabilities Dissertation-Abstracts-International Jan-Feb: Vol 34(1): 66-78.

[23]. Salovey, P. \& Mayer, J. D. (1989-90). 'Emotional intelligence,' Imagination, Cognition and Personality, 9. 185-211. Scale. Intelligence. Vol 29(5): 373-388.

[24]. Sameer, Babu M. (2008). Self-Esteem and Emotional Intelligence among B.Ed Trainees of Tsunami Affected Coastal Belt. Online Submission Research Report, ERIC Ref. No (ED500834)

[25]. Shakya, A. (2009). A study of teaching effectiveness of prospective teachers in relation to their emotional intelligence. Unpublished M.Ed. dissertation of Agra University

[26]. Sharma, S. (2003). A Study of Emotional Intelligence of Pupil Teachers in Relation to SES, Caste and Gender. M.Ed. dissertation, Bundelkhand University, Jhansi.

[27]. Sibia, A., Srivastava, A.K. \& Mishra, G. (2004). Towards understanding emotional intelligence in the Indian context. Psychological Studies, 49, (2-3), 68-77.

[28]. Singaravelu, S. (2011). Emotional Intelligence of Student teachers at Primary level in Pundcherry region. Unpublished Doctoral thesis. New Delhi, Jamia Millia Islamia University.

[29]. Singh R. (2003). A Study of Emotional Intelligence and Adjustment of Teachers but in different level of Education. M.Ed. Dissertation D.E.I. Agra

[30]. Tapia, M. and Marsh, G. (2001) Emotional Intelligence: The Effect of Gender, GPA and Ethnicity. Paper Presented at the Annual Meeting of the Mid-South Educational Research Association,Mexico. (ED464086).

[31]. Tucker, M.L., Sojka, J.Z., Barone, F.J. \& McCarthy, A.M. (2000). Training tomorrow's leaders: Enhancing the emotional intelligence of business graduates. Journal of Education for Business, 75(6), 331-338.

[32]. Upadhyaya, P. (2006). Personality of emotionally intelligent student-teachers. Journal of Educational Studies, 4 (1 \& 2), $37-39$.

[33]. Yate, Martin (1997). Career Smarts, Jobs with a future, Ballantine. 